Jarmo Saarti, Katri Rintamäki ja Kaisa Hartikainen

\title{
Eurooppalaiset yliopistoverkostot tarjoavat uusia mahdollisuuksia kirjastojen kehittämiseen
}

Eurooppalainen yhteistyö yliopistojen ja kirjastojen välillä kehittyy nopeasti. Komission tavoitteena on rakentaa alhaalta ylöspäin suuntautuvia yliopistoverkostoja, jotka lisäävät innovaatioita ja rajat ylittävää yhteistyötä. Itä-Suomen yliopiston (UEF) kirjasto lähti mukaan yliopistoliittouma YUFEn yhteistyöhön rakentamalla avoimen tieteen verkkokurssin eurooppalaiselle virtuaalikampukselle. UEF:n kokemukset olivat positiivisia: Pioneereille on saatavilla hyvin rahoitusta hanke- ja kehittämistoimintaan ja kirjastojen kannattaakin olla aktiivisia integroitumisessa eurooppalaisiin käytänteisiin.

$\mathrm{E}$ urooppalaisella korkeakoulujen yhteistyöllä on pitkät perinteet. Eu:n myötä yhteistyö on tiivistynyt. Vuonna 1999 aloitettu Bolognan prosessi käynnisti valmistelun, jolla pyrittiin harmonisoimaan korkeakoulujen tutkintorakenteet. Vuonna 20 Io otettiin seuraava askel korkeakoulujen yhteistyössä, kun perustettiin Eurooppalainen korkeakoulualue (EHEA). Tutkimuksessa vastaava rakenne on $\mathrm{Eu}$ rooppalainen tutkimusalue (ERA). Komission päämääränä on, että vuoteen 2025 mennessä rajat eivät olisi enää esteinä opiskelulle toisessa jäsenmaassa.

Komissio työskentelee parhaillaan yhdessä jäsenvaltioiden ja niiden korkeakoulutoimijoiden kanssa Eurooppa-yliopistojen kehittämiseksi. Tavoitteena on, että Eurooppa-yliopistot muodostaisivat alhaalta ylöspäin suuntautuvia yliopistoverkostoja. Verkostojen tarkoituksena on tehostaa rajat ylittävää yhteistyötä. Samalla ne edistäisivät laadukkaiden innovaatioiden syntyä, lisäisivät opiskelijoiden ja opettajien liikkuvuutta sekä tukisivat eurooppalaisten kielten oppimista.

Suomalaiset korkeakoulut ja niiden kirjastot ovat toimineet erilaisissa verkostoissa myös Euroopassa, tärkeimpänä kattojärjestönä LIBER, eurooppalaisten tutkimuskirjastojen järjestö. Eu:n myötä myös kirjastojen välinen yhteistyö on lisääntynyt ja siinä on auttanut korkeakoulujen henkilöstön liikkuvuutta tukeneet rahoitukset. Nyt alkaa aktivoitua edellä mainittujen yliopistoverkostojen luominen.

Itä-Suomen yliopisto mukana YUFEssa

Young Universities for the Future of Europe (yuFE, https://yufe.eu/) on yksi 4I eurooppalaisesta yliopistoliittoumasta, joille Euroopan komissio on myöntänyt rahoitusta Eurooppa-yliopistomallin kehittämiseen ja toteuttamiseen. Eurooppa-yliopistoaloite on yksi lippulaivahankkeista eurooppa- 
laisen koulutusalueen rakentamiseksi vuoteen 2025 mennessä. Erasmus+ ja Horisontti 2020 -rahoitusten avulla pilottiyliopistoliittoumat kehittävät eurooppalaisen korkeakoulutuksen laatua, osallistavuutta, digitalisaatiota ja houkuttelevuutta.

Itä-Suomen yliopisto (UEF) on yksi YUFE-liittouman kymmenestä yhteistyöyliopistosta. YUFE-verkostoa koordinoi Maastrichtin yliopisto Hollannista. Itä-Suomen ja Maastrichtin yliopistojen lisäksi mukana ovat Antwerpenin yliopisto Belgiasta, Bremenin yliopisto Saksasta, Essexin yliopisto Isosta-Britanniasta, Kyproksen yliopisto, Nicolaus Copernicus -yliopisto Puolasta, Rijekan yliopisto Kroatiasta, Carlos III Madrid -yliopisto Espanjasta ja Rooman Tor Vergata -yliopisto Italiasta sekä ei-akateemisina yhteistyökumppaneina koulutuksen arviointipalveluja tarjoava Educational Testing Service, eurooppalaisten yrittäjien liitto European Entrepreneurs CEA-PME, turvapaikanhakijoiden koulutusta edistävä Kiron Open Higher Education for Refugees sekä henkilöstöpalveluyritys Adecco Group.

\section{Yhteistyötä kahdeksassa teemapaketissa}

YUFE avaa yliopistojen opiskelijoille ja henkilöstölle uusia mahdollisuuksia kansainvälistymiseen mm. henkilövaihtojen ja virtuaalikurssien kautta, mutta myös tiiviimpää yhteistyötä tutkimus- ja innovaatiotoiminnassa ja laatutyössä sekä yhteyksien vahvistamista ympäröiviin alueisiin. YUFE-liittouman työ jakautuu kahdeksaan työpakettiin: projektihallinta; laatutyö; opiskelijaliikkuvuus; henkilöstöliikkuvuus; innovaatiotoiminta ja yrittäjyys; YUFE kaupungeissamme; diversiteetti ja inklusiivisuus; sekä kestävä kehitys ja disseminaatio.

Itä-Suomen yliopisto vastaa yUFE kaupungeissamme -työpaketista, joka pyrkii lisäämään vuorovaikutusta kampuskaupunkien kanssa. Lisäksi Itä-Suomen yliopisto on osavastuussa laatutyöhön liittyvästä työpaketista ja toimii aktiivisesti kaikissa yUfEn työpaketeissa. Eri työpakettien alla toimii teemoittain jaoteltuja työryhmiä, mm. kirjastotyöryhmä, jossa myös Itä-Suomen yliopiston kirjastolla on edustus.

Marraskuussa 202I julkaistiin YUFE-virtuaalikampus, jonka kautta yliopistoliittouman opiskelijat voivat ilmoittautua muiden YUFE-yliopistojen kursseille. yufEn muille sidosryhmille ja toiminta-alueille on tulossa omat portaalinsa. Monikielisyys toimii perustana monimuotoiselle ja yhtenäiselle eurooppalaiselle yliopistolle.

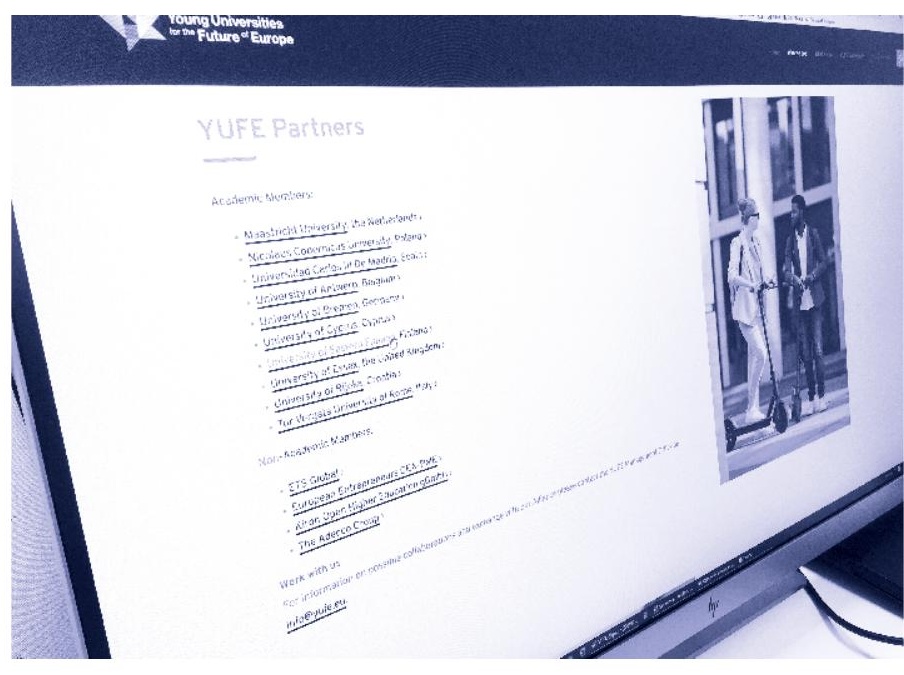


YUfE Open Programme -opintojen pääasiallinen opetuskieli on englanti. Lukuvuonna 202 I-2022 yUfEn yli 400 yliopistokurssista yli 65 kurssin opetuskieli on kuitenkin muu kuin englanti. Lisäksi YUFE tarjoaa yli 6o kielikurssia. YUFE-yliopistojen henkilöstölle YUFEn tavoitteena on luoda mahdollisuuksia oppimiseen, matkustamiseen, työskentelyyn ja urakehitykseen, mm. tarjoamalla kielikursseja, hen-

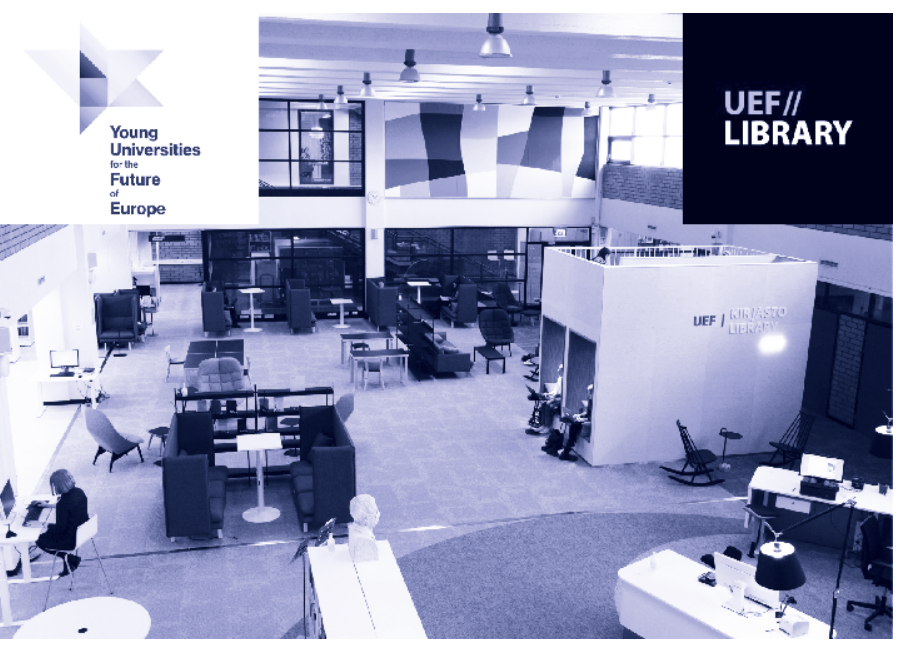

kilöstökoulutuksia, henkilöstö- ja opettajavaihtoja, työn havainnointia, harjoitteluja, mentorointia, tutkimusprojekteja ja tieteellistä yhteistyötä joko fyysisinä tai virtuaalisina vierailuina kaikissa YUFE-yliopistoissa. YUFE Academy -luennot, työpajat ja kielikurssit ovat jo avoimia sekä YUFE-yliopistojen opiskelijoille että henkilökunnalle.

\section{YUFE-kirjastojen yhteistyö}

YUFEn kirjastotyöryhmä aloitti toimintansa toukokuussa 202 I Antwerpenin yliopiston kirjaston koordinoimana. Kirjastotyöryhmä selvittää YUFEn opiskelijoille ja henkilökunnalle tarjottavia kirjastopalveluita ja kirjastojen välisiä yhteistyömahdollisuuksia. Monet YUFE-yliopistoliittoumalle keskeiset kirjastopalvelut ovat jo olemassa olevia, perinteisiä kirjastopalveluja:

- pääsy kunkin yliopiston kirjastoluetteloon vapaasti verkossa

- kaukopalvelu

- e-aineistojen käyttömahdollisuus (yliopiston paikalliskäyttäjänä tai opiskelija/henkilökuntastatuksen perusteella)

- yliopistojen julkaisuarkistojen hyödyntäminen

- yliopiston arkisto- ja kulttuuriperintökokoelmien saatavuus

- scan-on-demand-palvelu esim. yliopiston arkistokokoelmien aineistoista.

Erityisen kiinnostava on Antwerpenin yliopiston kirjaston esittämä agenda yUFE-kirjastojen välisestä koulutusyhteistyöstä. Koulutusyhteistyömahdollisuuksia olisivat kirjastojen väliset henkilökuntavaihdot, kirjastojen tuottamien informaatio- ja medialukutaidon verkkokurssien vaihtaminen ja kirjastojen henkilöstön kouluttamisen parhaiden käytäntöjen jakaminen.

Parhaiden käytäntöjen jakaminen on tärkeää siksi, että vaikka monissa maissa kirjastokoulutusta annetaan yliopistoissa kandidaatti-, maisteri- ja tohtoritutkinnonkin tasolla, niin esimerkiksi Alankomaissa ja Belgian Flanderissa kirjastoalan koulutusta ei enää 
anneta korkeakouluissa. Näissä maissa kirjastoihin rekrytoitu henkilöstö koulutetaan työssäoppimisen kautta kirjastojen omassa ohjauksessa. Kirjastoala myös kehittyy nopeasti: myös osaamisen päivittämiseen ja ajan tasalla pysymiseen ammattiyhteisön sisäinen vertaisoppiminen on tehokas keino.

\section{Kirjasto YUFEn opetustoiminnassa}

tä-Suomen yliopisto tarjosi eurooppalaisella virtuaalikampuksella jo lukuvuonna 2020-202I yhteensä kolmetoista verkko-opintojaksoa. Näistä yksi on Itä-Suomen yliopiston kirjaston toteuttama kahden opintopisteen laajuinen, jatko-opiskelijoille suunnattu Basics of Open and Responsible Science: Open Access Publishing and Research Data -verkkokurssi. Opintojaksoa pilotoitiin ensimmäisen kerran lukuvuonna 2020-202 I ja opintojakso järjestetään taas kuluvana lukuvuonna $202 \mathrm{I}-2022$.

Itä-Suomen yliopiston kirjasto vastaa opetuksen toteuttamisesta, mutta oppimateriaali tuotettiin yhdessä yliopiston muiden asiantuntijoiden, kuten tietosuojavastaavan ja tutkimusetiikan erityisosaajien, kanssa. Jo tämä yhteistyö osoitti, että avoin tiede ei ole vain kirjaston asia, vaan koskettaa tavalla tai toisella useita eri alojen asiantuntijoita, tutkijoiden lisäksi tietenkin. Opintojakson oppimateriaali on avoimesti kaikkien hyödynnettävissä, joten avoimen tieteen perusteisiin voivat perehtyä kaikki aiheesta kiinnostuneet.
Pilotointivaiheessa keväällä 202 I opintojakso oli mahdollista suorittaa itsenäisesti omaan tahtiin opiskellen, ja näin toteutamme opintojakson jatkossakin. Opintojakson suoritti 59 Itä-Suomen yliopiston ja neljä YUFE-verkoston jatko-opiskelijaa. tuminen opintojakson suorittamiseen oli ilo havaita ja kannustaa jatkamaan yhteistyötä. Vaikka opintojakso suoritettiin verkossa itsenäisesti opiskellen, oppimistehtävien myötä opiskelijoiden oli mahdollista tutustua avoimen tieteen käytäntöihin ja toimintatapoihin eri puolella maailmaa. Myös tähän YUFE-verkoston opiskelijat toivat oman mausteensa. Opettajan näkökulmasta YUFE-opiskelijoiden osallistuminen oli sujuvaa ja YUfElaiset ovat lämpimästi tervetulleita opintojaksolle myös alkavana lukuvuotena.

Kirjasto YUFEn tutkimus- ja innovaatiotoiminnassa

V

uonna 2020 yUfE-yliopistoverkosto sai kahden miljoonan euron lisärahoituksen verkoston tutkimus- ja innovaatioulottuvuuden kehittämiseen. Verkoston yUfERING-hanke (YUfE Transforming Research and Innovation through Europe-wide KNowledGe Transfer) sai rahoitusta erityisesti eurooppalaisille yliopistoliittoumille suunnatusta Horisontti 2020 -ohjelman Science with and for Society (SwafS) -hausta. Hanketta koordinoi Kyproksen yliopisto.

YUFERING-hankkeessa tavoitteena on laatia tutkimus- ja innovaatiojärjes- 


\section{4}

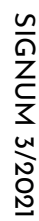

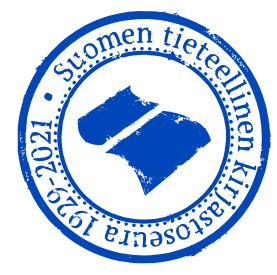

telmämalli, joka tuo yhteen eurooppalaisia yliopistoja ja niiden tutkimus- ja innovaatioekosysteemejä tiedonsiirron, yhteisöjen osallistamisen ja kaikki alat, sidosryhmät ja maat kattavan yhteistoiminnan kautta. Hanke pyrkii myös edistämään YUFE-liittouman yhteisen tutkimus- ja innovaatio-ohjelman kehittämistä, yliopistojen ja yritysten välistä yhteistyötä ja avointa tiedettä.

Itä-Suomen yliopisto koordinoi YUFERING-hankkeen tutkijoiden tunnustus- ja palkitsemisjärjestelmää sekä avoimen tieteen suoritteiden arvioinnin indikaattoreita koskevia alahankkeita. Tavoitteena on kehittää tutkijoiden tunnustus- ja palkitsemisjärjestelmämalli, joka sisältää laadullisen ja avoimen tieteen suoritteiden arvioinnin kriteeristön huomioiden tutkijan ansiot erityisesti yhteiskunnallisen osallistumisen ja avoimen tieteen edistämisessä. Itä-Suomen yliopiston kirjasto osallistuu Itä-Suomen yliopiston koordinoimiin YUFERING-alahankkeisiin erityisesti avoimen tieteen kysymysten osalta, joita hankkeessa kartoitetaan mm. dokumenttianalyysin, kyselyiden ja haastattelujen kautta.

\section{Päätäntö}

UEF:in kirjaston kokemusten perusteella näyttää siltä, että eurooppalainen yhteistyö yliopistojen ja niiden kirjastojenkin välillä kehittyy nopeasti. Lisäksi pioneereille on saatavilla hyvin rahoitusta hanke- ja kehittämistoimintaan. Kirjastojen kannattaakin olla aktiivisia toimintojensa kehittämisessä ja integroimisessa eurooppalaisiin käytänteisiin. Hankeyhteistyö tarjoaa kirjastoille uusia mahdollisuuksia kansainvälistymiseen, yhteistyösuhteiden ja verkostojen luomiseen ja osaamisen kehittämiseen. Omassa yliopistossa kirjastolla on tätä kautta mahdollista kasvattaa merkitystään ja jakaa asiantuntemustaan.

Avoin tiede ja sen käytännöt tukevat hyvin sekä poliittisia linjauksia, että käytännön palveluiden kehittämistä. Avoimesti käytettävissä olevat aineistot ja avoin oppiminen ovat suuri mahdollisuus uudenlaisen eurooppalaisen verkostoituneen yliopistolaitoksen kehittämiselle. Kirjastoilla on tässä osaamisensa puolesta merkittävä rooli otettavana.

\title{
Lähteet:
}

Basics of Open and Responsible Science: Open Access Publishing and Research Data -verkkokurssi. Itä-Suomen yliopisto. https://blogs.uef.fi/ueflibrary-bors/ yufe. https://www.uef.fi/fi/yufe

\author{
Kirjoittajat \\ JARMO SAARTI \\ Itä-Suomen yliopiston kirjasto \\ jarmo.saarti@uef.fi
}

KATRI RintAMÄKI

Itä-Suomen yliopiston kirjasto

katri.rintamaki@uef.fi
Kaisa Hartikainen

Itä-Suomen yliopiston kirjasto

kaisa.hartikainen@uef.fi 